\title{
Cationic polymers in water treatment Part 2: Filterability of CPE-formed suspension
}

\author{
P Polasek ${ }^{1 *}$ and S Mutl ${ }^{2}$ \\ ${ }^{1}$ P Polasek \& Associates, Consulting Engineers, P O Box 61965, Marshalltown 2107, South Africa \\ 2 Institute of Hydrodynamics, Academy of Sciences of the Czech Republic, Pod Patankou 5, 16612 Praha 6, Czech Republic
}

\author{
Abstract \\ Part 2 of the paper compares filterability of CPE-formed and mineral coagulant-formed suspensions.
}

\section{Introduction}

The aim of coagulation is not only the formation of a readily settleable suspension, but also a suspension which is effectively filterable in order to obtain economic operation of filtration plants.

Particle aggregation and deep-bed filtration are interrelated processes because the effectiveness of filtration is determined by the properties of the formed aggregates. Those properties which are favourable for effective sedimentation may not necessarily be the most suitable for effective filtration and vice versa.

Suspensions of four different properties in respect of their filterability can be formed. A suspension which is completely retained in the filter bed at the expense of high head loss is not desirable. Similarly, a suspension which generates a low head loss but is poorly retained is also not desirable. A suspension which is poorly retained and generates high head loss is the worst of all. A suspension which is completely retained and generates a minimum head loss represents an ideal suspension, the formation of which should be aimed at.

The filterability of CPE-formed suspension compared with that of hydrolysing coagulant formed suspension is investigated in this paper.

\section{Pilot plant}

The pilot tests were carried out in a plant consisting of two complete filtration plants, each comprising a flocculation chamber and a filtration column. The plant arrangement is shown in Fig. 1 and Picture 1.

The flocculation chamber (A) was made of a $1000 \mathrm{~mm}$ long perspex tube with an inner diameter $\mathrm{D}_{\mathrm{FC}}=125 \mathrm{~mm}$ and bottom inlet. It was furnished with a double frame, double anchor, two tier type stirrer (6) driven by a variable speed drive (7).

The filtration column (B, C) was made of $2750 \mathrm{~mm}$ long perspex tube of $100 \mathrm{~mm}$ inner diameter. This column was provided at the top with an inlet connection (8) to the filter column and a drain overflow (9) maintaining the operating water level in the filter column constant. At the bottom, the filter column was provided with a false floor (10), drilled with 70 evenly spaced $1 \mathrm{~mm}$ diameter holes, on which the filter medium rested. The filtrate discharge (13) was below the false floor (10) on the bottom of of the column. The

* To whom all correspondence should be addressed.

政(011) 642-5727; fax: (011) 484-2187; e-mail: polasek@mweb.co.za Received 22 March 2001; accepted in revised form 30 September 2001. filter column was also provided with side taps (11) $100 \mathrm{~mm}$ apart for measurement of head loss through the filter bed depth; the lowest point was located $40 \mathrm{~mm}$ above the false floor. The loss of head was measured in a tube type pressure gauge (12). During testing, one of the filter columns was charged with sand only and the other one with sand and Hydro-anthrasit " $H$ ". The single medium filter column was charged (B1) with silica sand of grade 1.0 to $2.0 \mathrm{~mm}, \mathrm{~d}_{50}=1.315 \mathrm{~mm}, \mathrm{UC}<1.25$ to a depth $\mathrm{L}_{\mathrm{F}}=1150 \mathrm{~mm}$. The operating water depth was $\mathrm{L}_{\mathrm{w}}=1600 \mathrm{~mm}$. The dual media filter column was charged with (C1) Hydro-anthrasit " $\mathrm{H}$ " of grade $1.6-2.5 \mathrm{~mm}, \mathrm{~d}_{50}=2.035 \mathrm{~mm}$, UC $<1.4$ to a depth $\mathrm{L}_{\mathrm{F}}=1040 \mathrm{~mm}$ and (C2) silica sand of grade 0.7 to $1.1 \mathrm{~mm}, \mathrm{~d}_{50}=0.91 \mathrm{~mm}$, UC $<1.30$ to a depth $\mathrm{L}_{\mathrm{F}}=440 \mathrm{~mm}$. The operating water depth was $\mathrm{L}_{\mathrm{w}}=1270 \mathrm{~mm}$.

The bottom discharge (13) from the filter column (B, C) was connected to a positive displacement gear type pump (14) and driven by a variable speed drive. The gear pump was selected to ensure that the pre-set rate of flow through the filtration column was maintained constant at all times, irrespective of the loss of head generated by the filter bed during the filtration runs. The electrically controlled variable speed drive was used to vary the capacity of the gear pump, allowing selected preset flow rates through the filtration column.

Raw water inlet (1) to the plant was arranged via a flash mixing device consisting of a T-piece (3) and three valves $(2,4)$, one at each end of the T-piece (3). Each discharge (5) from the T-piece (3) was fitted with a valve (4) and connected via piping (5) to one of the flocculation chambers (A). The rate of flow to the pilot plant was measured upstream of the flash mixer and controlled by operating the inlet valve (2). The total flow through the pilot plant was split into each filtration unit at the T-piece (3). The valves (4) were used to control and balance the flow rate through the flocculation chambers (A). Discharge (8) from the flocculation chamber (A) was connected to the top of the filtration column $(B, C)$. The flow control was designed to provide the same flow to each flocculation chamber. This was achieved as follows. The total flow through the pilot plant was slightly greater than that filtered by both filters. The portion of the flow of flocculated water that exceeded the filtered flow was drained continuously from the top of each filter column (9). The flow through each flocculation chamber was adjusted by the inlet valve (4) to the flocculation chamber in such a way that the flow drained from the top of each filter column was approximately the same, and hence, the retention times in both flocculation chambers were also approximately the same. The loss of head was measured by a tube-type pressure gauge (12). 

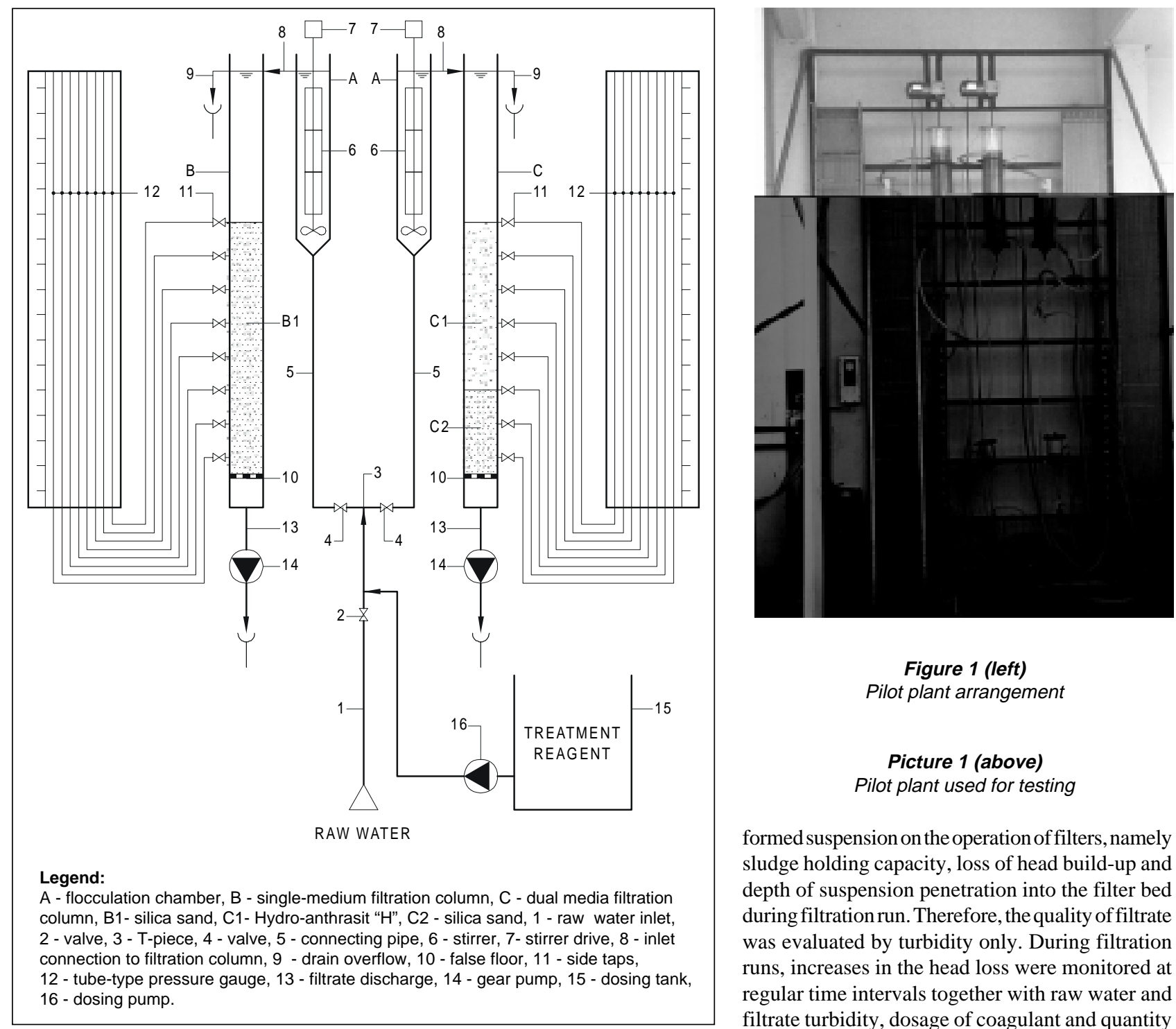

Figure 1 (left)

Pilot plant arrangement

Picture 1 (above)

Pilot plant used for testing

formed suspension on the operation of filters, namely sludge holding capacity, loss of head build-up and depth of suspension penetration into the filter bed during filtration run. Therefore, the quality of filtrate was evaluated by turbidity only. During filtration runs, increases in the head loss were monitored at regular time intervals together with raw water and filtrate turbidity, dosage of coagulant and quantity of suspension entering the filter.

The coagulant was dosed from a tank (15) with a metering pump (16). The coagulant dosing point was located upstream of the flash mixer next to the inlet valve (2). Homogenisation of the added reagent with water was achieved by means of turbulence generated mainly by means of the throttled inlet valve (2). The intensity of agitation in the flocculation chamber was controlled by varying the speed of the stirrer. During the tests, the stirrers (6) in both flocculation chambers (A) were running at the same speed, thus providing the same conditions of agitation for the aggregation of impurities.

The two filtration plants were operated in parallel using the same dosage by the same coagulant. The rate of flow through the filtration column (B) was volumetrically measured at the discharge from the pump (14). Both pumps (14) were set to pump at the same rate.

After placing the medium, each filter was backwashed and the fine grains removed from the top of the filter bed. After completion of a filtration run, the filter medium used was replaced with a new charge.

\section{Plant performance evaluation}

The purpose of this study was to establish the influence of CPE
Samples of both the flocculated water entering the filter and the filtrate produced were taken at regular intervals. The head loss readings were taken at the same time as water samples. The filtration run ended due to either turbidity breakthrough or utilisation of the available pressure head, whichever occurred first. The results obtained were processed and plotted in the form of a Michau-type pressure diagram.

For calculation of the sludge-holding capacity of the filter bed $K_{S}$ the following equation was developed:

$$
K_{S}=\frac{T_{F} v_{F} c_{S S}}{L_{F}}
$$

where:

$T_{F}$ - duration of filtration run $[\mathrm{h}]$

$v_{F}-$ filtration velocity $\left[\mathrm{m} \cdot \mathrm{h}^{-1}\right]$

$c_{S S}$ - concentration of suspended solids at the inlet to the filter $\left[\mathrm{kg} \cdot \mathrm{m}^{-3}\right]$

$L_{F}-$ depth of filtration layer [m].

The mean velocity gradient $\overline{\mathrm{G}}$ existing in the filter bed was calculated from the following equations (Polasek, 1979):
$K_{s}$ - sludge-holding capacity $\left[\mathrm{kg} \cdot \mathrm{m}^{-3}\right]$ 


$$
\bar{G}=\sqrt{\frac{\Delta h_{F} g}{v T_{F}}}=\sqrt{\frac{\Delta h_{F} g v_{F}}{v L_{F} \omega}}
$$

where:

$\overline{\mathrm{G}} \quad$ - mean velocity gradient in the clogged layer of the filter bed $\left[\mathrm{s}^{-1}\right]$

$\Delta \mathrm{h}_{\mathrm{F}}$ - head loss generated by flow through the filtration layer $L_{F}[\mathrm{~m}]$

$T_{F} \quad$ - retention time in the filtration layer $[\mathrm{s}]$

$\omega$ - porosity of the filter medium [-]

$v \quad$ - kinematic viscosity $\left[\mathrm{m}^{2} \cdot \mathrm{s}^{-1}\right]$

$g \quad$ - gravity constant $\left[\mathrm{m} \cdot \mathrm{s}^{-2}\right]$.

The porosity $\varepsilon$ of the clogged filtration layer was calculated from the Kozeny-Carman equation (Tesarik, 1961):

$$
\begin{aligned}
\Delta h_{F} & =\frac{36 K_{m} v_{F} v L_{F}(1-\omega)^{2}}{g s^{2} d_{g}^{2} \omega^{3}} \\
K_{m} & - \text { filter medium constant, taken as 5.0 [-] } \\
d_{g} & - \text { filter medium grain diameter [m] } \\
s & - \text { filter medium grain sphericity factor [-]. }
\end{aligned}
$$$$
\text { where: }
$$

The term "water treatment" is used in this article in the commonly accepted context of "water treatment".

\section{Pilot-plant testing}

The filtration tests were carried out at the Witbank Waterworks during February - March 1983 (Polasek, 1983). The source of raw water was the Witbank Dam. During testing, the raw water was characterised by a total turbidity varying between $\mathrm{Tu}_{\mathrm{RW}}=12$ to 14 NTU and that produced by a non-separable portion of impurities (Hereit et al., 1977; Hereit and Mutl, 1980; Polasek, 1980) between $\mathrm{Tu}_{\mathrm{RW}} \mathrm{F}=6.5-6.6 \mathrm{NTU}$. The organic pollution of the raw water, measured in a spot sample, was characterised by dissolved organic carbon $\mathrm{DOC}=4.5 \mathrm{mg} \mathrm{C} \cdot \ell^{-1}$ and total organohalogens by the terminal value of $\mathrm{TOH}_{\mathrm{T}}=59 \mu \mathrm{g} \mathrm{CHCl}_{3} \cdot \ell^{-1}$ and the potential (organohalogen precursors) value of $\mathrm{TOH}_{\mathrm{P}}=544 \mu \mathrm{g} \mathrm{CHCl}_{3} \cdot \ell^{-1}$ (Private communication, 1983). Temperature of the raw water was $\mathrm{t}^{\mathrm{RW}}=24.5^{\circ} \mathrm{C}$.

The filtration plants were operated in parallel, always filtering the same water treated under the same reaction conditions and the impurities aggregated under the same conditions of agitation. One series of filtration tests was carried out with ferric chloride and another one with a polyamine type CPE with a trade name Organol.

\section{Ferric chloride}

The raw water turbidity was, $\mathrm{Tu}_{\mathrm{RW}}=12 \mathrm{NTU}$ and $\mathrm{Tu}_{\mathrm{RW}} \mathrm{F}=6.5 \mathrm{NTU}$ respectively. Ferric chloride was applied at a dosage $\mathrm{D}=19 \mathrm{mg} \cdot \ell^{-1}$. The quantity of suspension entering the filter averaged $\mathrm{c}_{\mathrm{SS}}=15.9$ $\mathrm{mg} \cdot \ell^{-1}$. The plant was operated at a filtration velocity $\mathrm{v}_{\mathrm{F}}=6.56 \mathrm{~m} \cdot \mathrm{h}^{-1}$. The residual turbidity in the filtrate varied between $\mathrm{Tu}_{\mathrm{F}}=0.2$ to 0.35 NTU. The filtration run ended when residual turbidity in the filtrate exceeded $\mathrm{Tu}_{\mathrm{Fmax}}=0.40 \mathrm{NTU}$.

The results obtained with the single medium filter and plotted in the form of the Michau-type pressure diagram are shown in Fig. 2 and with the dual media filter in Fig. 4 (Polasek, 1983).

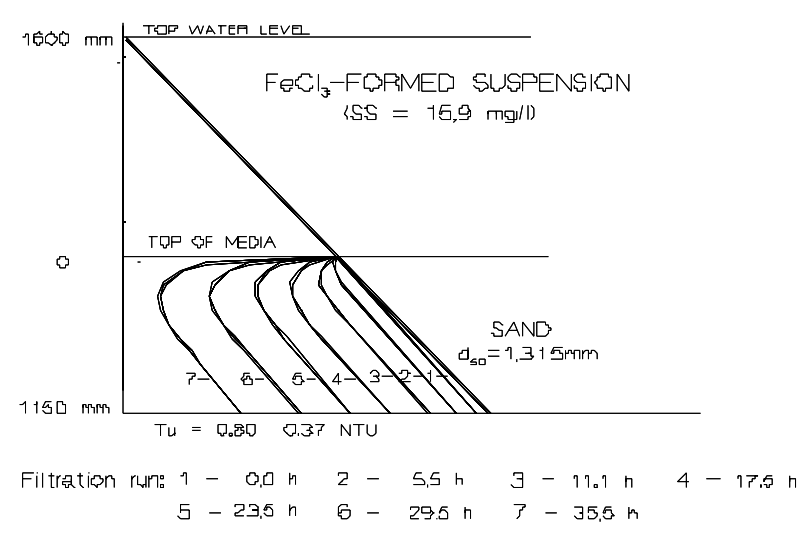

Figure 2

Pressure diagram according to Michau - single-medium filter Filtration velocity $=6.56 \mathrm{~m} \cdot \mathrm{h}^{-1}, \mathrm{TU}^{R W}=12 \mathrm{NTU}$

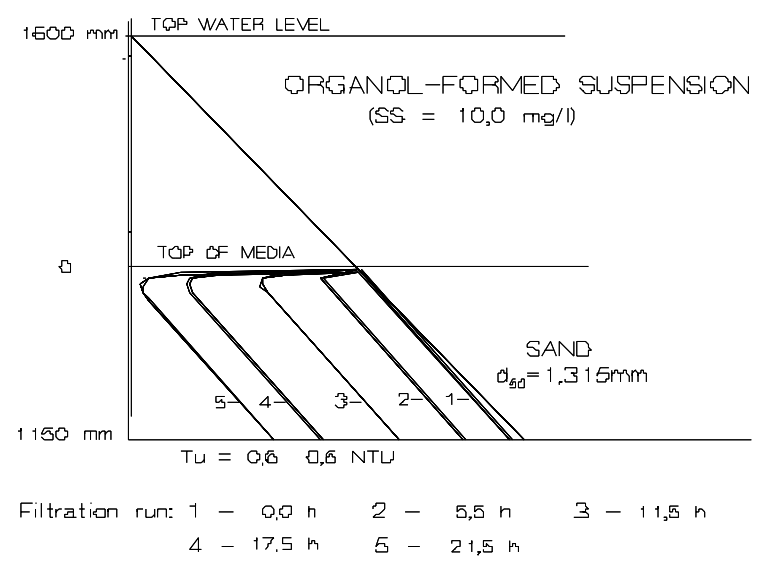

Figure 3

Pressure diagram according to Michau - single-medium filter Filtration velocity $=6.56 \mathrm{~m} \cdot \mathrm{h}^{-1}, \mathrm{TU}^{\mathrm{RW}}=14 \mathrm{NTU}$

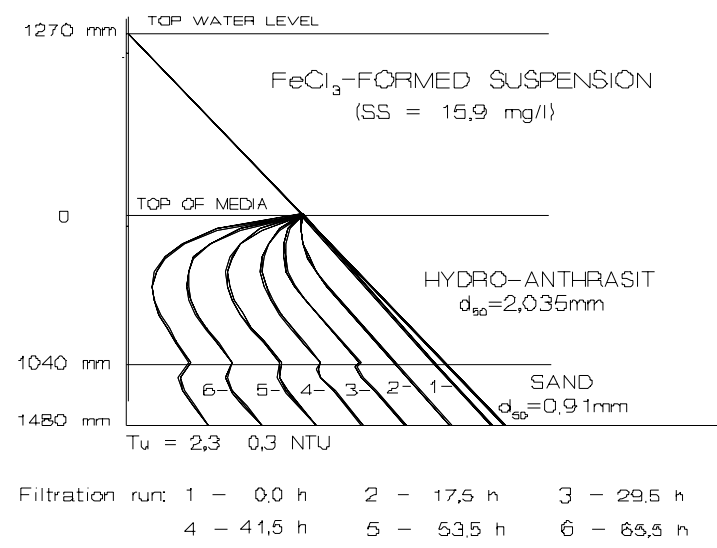

Figure 4

Pressure diagram according to Michau - dual media filter Filtration velocity $=6.56 \mathrm{~m} \cdot \mathrm{h}^{-1}, \mathrm{TU}^{\mathrm{RW}}=12 \mathrm{NTU}$

\section{Organol}

The average raw water turbidity was $\mathrm{Tu}_{\mathrm{RW}}=14 \mathrm{NTU}$ and $\mathrm{Tu}_{\mathrm{RW}} \mathrm{F}$ $=6.8$ NTU. Organol was applied at a dosage D $=0.95 \mathrm{mg} \cdot \ell^{-1}$. The quantity of suspension entering the filter averaged $\mathrm{c}_{\mathrm{ss}}=10.0$ 


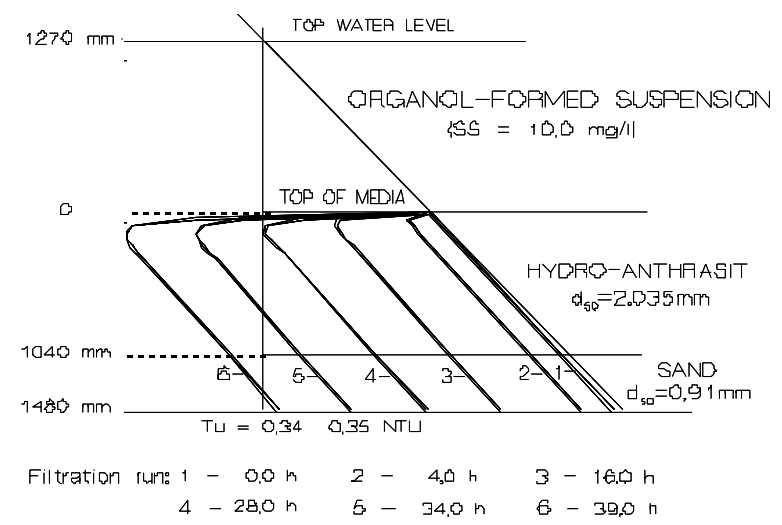

Figure 5

Pressure diagram according to Michau - dual-media filter Filtration velocity $=6.56 \mathrm{~m} \cdot \mathrm{h}^{-1}, T U^{R W}=14 \mathrm{NTU}$

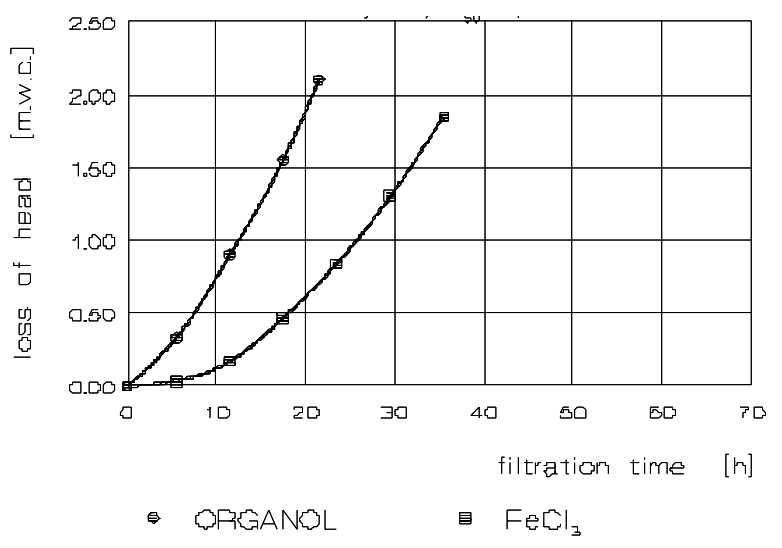

Figure 6

Dependence of head loss on filtration run - single-medium filter Sand: $L=1.15 \mathrm{~m}, d_{50}=1.315 \mathrm{~mm}$

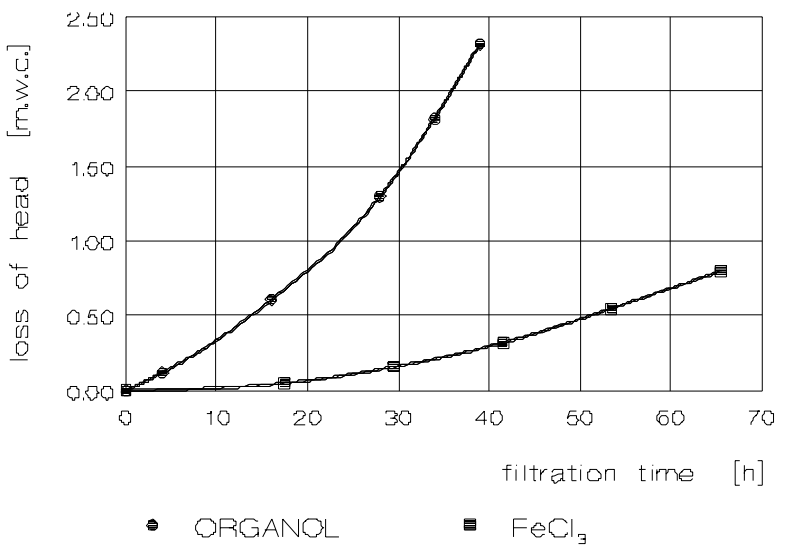

Figure 7

Dependence of head loss on filtration run - dual-media filter Anthrasit: $L=1.04 \mathrm{~m}, d_{50}=2.035 \mathrm{~mm} /$ Sand: $L=0.44 \mathrm{~m}$, $d_{50}=0.91 \mathrm{~mm}$

$\mathrm{mg} \cdot \ell^{-1}$. The plant was operated at a filtration velocity $\mathrm{v}_{\mathrm{F}}=6.56 \mathrm{~m} \cdot \mathrm{h}^{-1}$. The residual turbidity in the filtrate varied between $\mathrm{Tu}_{\mathrm{F}}=0.3$ to 0.6 NTU. The filtration run ended when residual turbidity in the filtrate exceeded $\mathrm{Tu}_{\mathrm{Fmax}}=0.60 \mathrm{NTU}$ or when the total pressure head available was utilised.

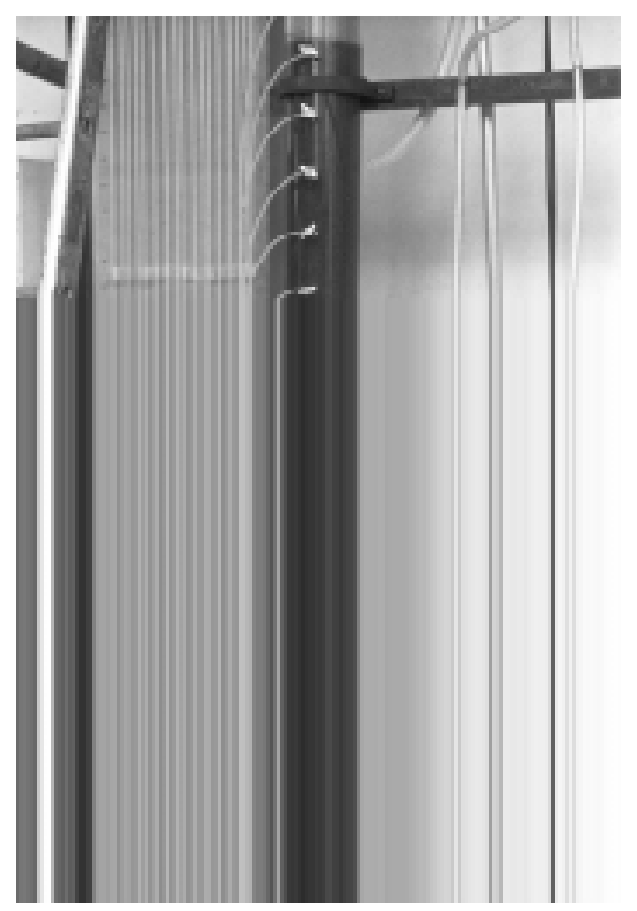

Picture 2

Interception of ferric chloride-formed suspension in the filter bed

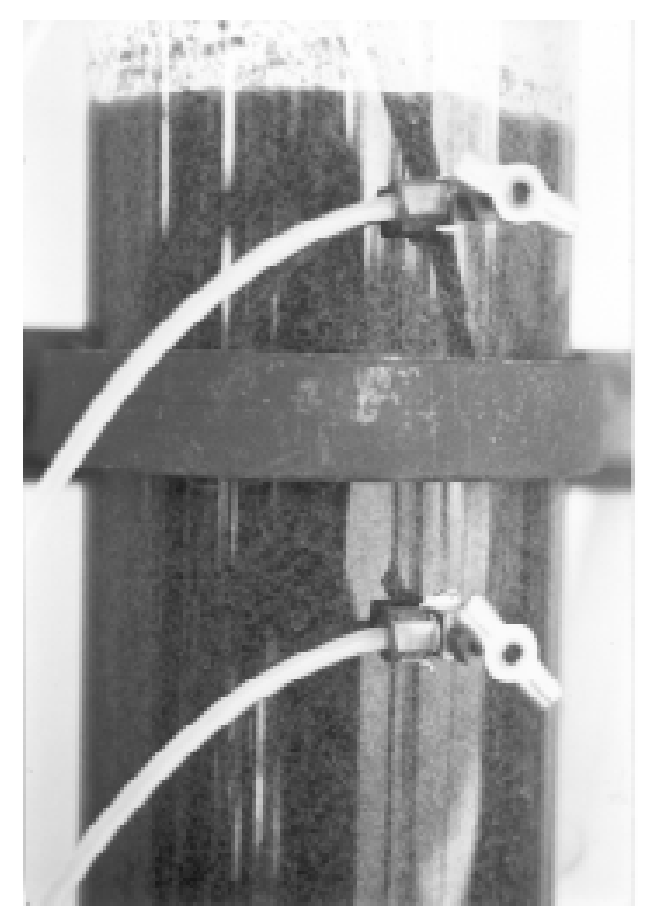

Picture 3

Interception of ferric chloride-formed suspension intercepted in the dual media filter column

The results obtained with the single-medium filter and plotted in the form of the Michau-type pressure diagram are shown in Fig. 3 and with the dual media filter in Fig. 5 (Polasek, 1983; Polasek and Mutl, 1995).

The effect of ferric chloride- and Organol-formed suspensions on head loss build-up for the single medium filter is compared in Fig. 6 and for the dual media filter in Fig. 7. 


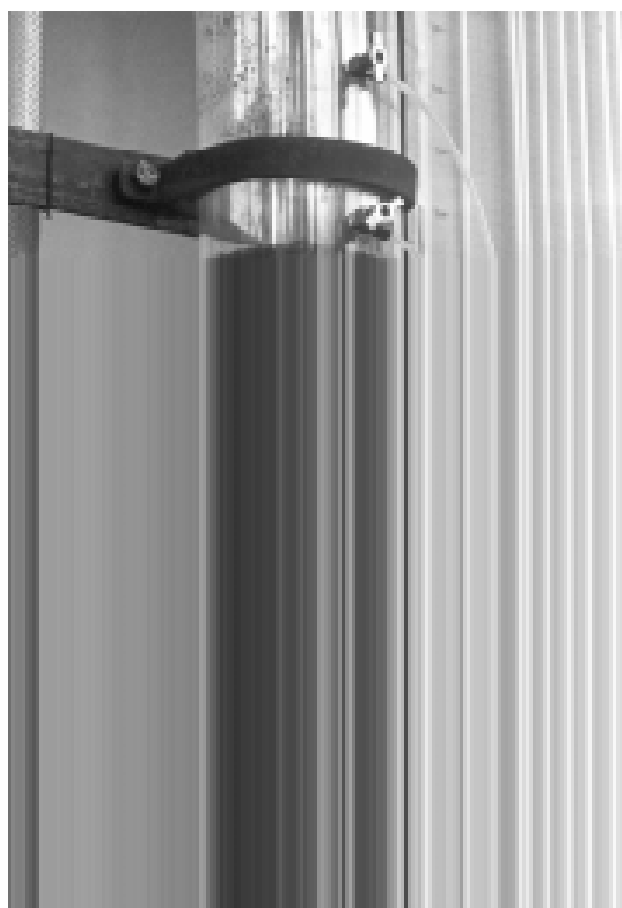

Picture 4

Interception of CPE Organol-formed suspension in the filter bed

\section{Discussion of the results obtained}

\section{Ferric chloride formed suspension}

The results obtained with the single-medium sand bed are shown in Fig. 2. This filter operated under a positive pressure at all times and the filtration run ended after $T_{F}=30 \mathrm{~h}$ due to the turbidity breakthrough, $\mathrm{Tu}>0.40 \mathrm{NTU}$. Suspension penetrated throughout the full depth of the filter bed.

The results obtained with the dual-media filter bed are shown in Fig. 4. This filter also operated under positive pressure at all times and the filtration run ended after $T_{F}=67 \mathrm{~h}$ also due to the turbidity breakthrough. Suspension penetrated easily throughout the full depth of the filter bed as is evident from the reddish colour of both Hydro-anthrasit " $\mathrm{H}$ " in Picture 2 and of otherwise white silica sand in Picture 3. The increase in head loss was slow for both single- and dual-media filters. Furthermore, it was observed that almost no suspension was deposited on the top of the filter bed. The backwashing of the filters did not cause any problem.

\section{Organol-formed suspension}

The results obtained with the single-medium sand bed are shown in Fig. 3. Residual turbidity in the filtrate below $T u_{F}=0.6 \mathrm{NTU}$ was not produced in the filtrate. Figure 3 shows that the single medium filter filtering the Organol-formed suspension operated under positive pressure and the filtration run ended after $T_{F}=21.5 \mathrm{~h}$ when the pressure head produced by the operating depth of water above the filter bed was utilised. At the end of the filtration run, suspension penetrated to a depth of about $140 \mathrm{~mm}$ only. There was a rapid increase in the loss of head.

The results obtained with the dual-media filter bed are shown in Fig. 5. Residual turbidity in the filtrate was below $T u_{F}=0.4 \mathrm{NTU}$ throughout the filtration run. As Fig. 5 shows, filtration was taking place under positive pressure during the first approximately $28 \mathrm{~h}$ of
TABLE 1

The square root mean velocity gradient $\bar{G}$ affecting suspension intercepted in filter bed at the end of filtration run

(filtration velocity $v_{F}=6.56 \mathrm{~m} \cdot \mathrm{h}^{-1}$, water temperature $\mathrm{t}=24.5^{\circ} \mathrm{C}$ )

\begin{tabular}{|l|c|c|c|}
\hline Filtration medium & \multicolumn{3}{|c|}{ Velocity gradient G [s-1] } \\
\cline { 2 - 4 } & $\begin{array}{l}\text { Clean } \\
\text { water }\end{array}$ & \multicolumn{2}{|c|}{$\begin{array}{c}\text { Suspension } \\
\text { formed by }\end{array}$} \\
\cline { 2 - 4 } & & FeCl $_{3}$ & Organol \\
\hline $\begin{array}{l}\text { Sand bed, d } \\
\text { Hydro-anthrasit'H" bed, } \\
\mathrm{d}_{50}=2.035 \text { mm }\end{array}$ & 41 & 368 & 1310 \\
1743 \\
\hline
\end{tabular}

operation. After about $28 \mathrm{~h}$ of operation, the pressure provided by the water head above the medium was fully utilised and filtration began to take place under subatmospheric conditions. The subatmospheric conditions deepened with filtration time and the filtration run ended after $T_{F}=39 \mathrm{~h}$ because the total pressure head available in the filter had been utilised. The Organol-formed suspension did not penetrate deep into the filter bed, even with the coarser filter medium provided by Hydro-anthrasit " $\mathrm{H}$ ", and at the end of the filtration run the intercepted suspension penetrated to a depth of about $180 \mathrm{~mm}$ only. The increase in head loss was very fast.

In contrast to ferric chloride, the Organol-formed suspension did not penetrate deep into the filter bed and was intercepted in the uppermost thin layer of the filter bed, as can be seen also in Picture 4. In the case of the single-medium filter, the Organol-formed suspension penetrated to a depth of about $140 \mathrm{~mm}$ only and in the case of the dual-media filter it penetrated to a depth of about 180 mm only. It was observed that a considerable quantity of suspension was intercepted on top of the filter bed in the form of a sludge membrane. In both cases, the single- and the dual-media filtration runs always ended due to the utilisation of the pressure head available. Interception of suspension was accompanied by a rapid build-up of head loss. Furthermore, this suspension was virtually impossible to remove effectively from the filter bed by backwashing.

Comparison of the results in Figs. 6 and 7 shows that the head loss build-up of the Organol-formed suspension was much more intensive than that obtained with the ferric chloride-formed suspension. The duration of filtration runs achieved with the ferric chloride-formed suspension was almost twice that of the Organolformed suspension.

The sludge-holding capacity of the Hydro-anthrasit " $\mathrm{H}$ " filter bed $\left(d_{50}=2.035 \mathrm{~mm}, \mathrm{UC}<1.4\right)$ was established to be $K_{S}=6.3$ $\mathrm{kg} \cdot \mathrm{m}^{-3}$ and for the silica sand bed $\left(d_{50}=1.315 \mathrm{~mm}, \mathrm{UC}<1.25\right) K_{S}$ $=2.3 \mathrm{~kg} \cdot \mathrm{m}^{-3}$ for the ferric chloride-formed suspension. The sludgeholding capacities were not calculated for the Organol-formed suspension, because such results would be misleading due to the formation of a sludge membrane on top of the filter bed of both single- and dual-media filters.

The velocity gradients and the shear stress acting on the suspensions intercepted in the filter beds, and calculated from the head loss generated by the clogged layer of the filter bed, according to Eqs. 2 and 3, are presented in Table 1.

The differences in the depth to which ferric chloride and Organol-formed suspensions penetrated into the filter bed originate from their different forces of attachment (adhesion) to the filter medium. Unlike the ferric-chloride formed suspension, the 
attachment forces of the Organol-formed suspension must be considerably greater than the shear forces produced by water flowing through the clogged thin layer of the filter bed because the intercepted suspension was withstanding these very high shear forces so effectively that they did allow the suspension to penetrate deep into the bed.

It also transpires from Figs. 2 to 7 that the smaller the suspension attachment forces, the deeper the suspension penetrates into the filter bed and the slower the head loss increase. Also, the slower the head loss increase, the more efficient is the backwash.

Therefore, it is not surprising that the Organol-formed suspension could not be removed effectively from the filter bed during backwashing. Filter backwashing aimed at recovering the sludge-holding capacity of the filter bed could not be accomplished. This is due to the shear forces produced by the flow during filter backwashing and the resulting rubbing effect on the medium grains produced. Even the most efficient air and water combined backwashing are not great enough to effect the loosening of the intercepted suspension from the medium grains. The Organolformed suspension adhered so strongly to the filter medium that its removal could not be accomplished effectively, not even by using unconventional methods such as rubbing the medium grains by hand under flowing water. The filter medium had to be replaced after each filtration run.

It also follows from the foregoing that the high filterability of CPE-formed suspensions will, most likely, enable installation of filters with a shallower bed depth and coarser filtration medium operating at higher filtration velocities than those used at present. Consequently, filtration plants would be smaller. As the filtration plant is usually the most expensive plant in the works, this upgrading of filtration plants will be most welcome because it should reduce the capital cost. On the other hand, the better the filterability the less effectively is the suspension loosened and washed away during backwashing. None of the present methods of filter backwashing is capable of removing the intercepted CPE-formed suspensions from filters. This is due to the shear forces generated during filter backwash being smaller than the suspension attachment forces, which the intercepted suspension withstands during filtration. Therefore, the attainable efficiency of filter backwashing is an important factor restricting the use of CPE in water treatment.

The results obtained from this study, together with the results and observations from other localities where CPE were used, enable us to draw the following more generalised conclusions:

\section{Conclusions}

1 Unlike hydrolysing reagents, the CPE-formed suspension does not penetrate deep into the filter bed and is intercepted in the uppermost thin layer of the filter bed. As blinding of the filter medium progresses, a sludge membrane is produced on top of the filter bed and the deep bed filtration process changes to that of straining.
2 The increase in head loss of CPE-formed suspension is much faster than that for hydrolysing reagent.

3 The working period of filtration runs, attained at the same generated head loss, was twice as long for the ferric chlorideformed suspension as that for the Organol-formed suspension (Figs. 6 and 7).

4 The CPE-formed suspension should not be filtered by filters with conventional grain size medium. Prior to resorting to the use of any CPE, all consequences that may result from such application with respect to plant operation and its overall performance efficiency should first be evaluated thoroughly.

5 It was observed that the smaller the suspension attachment forces, the deeper the suspension penetrates into the filter bed and the slower the increase in head loss. Furthermore, the slower the increase in head loss, the easier and more efficient is filter backwashing.

6 The CPE-formed suspension intercepted in the filter bed effectively withstands very high shear forces, corresponding to a mean velocity gradient greater than $\mathrm{G}=1700 \mathrm{~s}^{-1}$, without dragging suspension deep into the filter bed. This makes efficient filter backwashing extremely difficult, if not impossible

7 The high attachment forces of CPE-formed suspension make effective filter backwashing very difficult to accomplish by any traditional method.

8 Mud balls are always found in the filter bed when CPE-formed suspension is filtered. Their quantity and size are backwashing-, time- and procedure-dependent. They are a source of secondary pollution of the treated water.

\section{References}

HEREIT F and MUTL S (1980) Formation of separable suspension and methods of its evaluation. AQUA 5

HEREIT F, MUTL S and VAGNER V (1977) Hodnoceni provozu upraven vody (in Czech). J.Vodni hospodarstvi B 274.

POLASEK P (1979) The significance of the root mean square velocity gradient and its calculation in devices for water treatment. Water SA $\mathbf{5}$ (4) $196-207$.

POLASEK P (1983) Project Report - Municipality of Witbank: Technological Proposal for New Water Treatment Works, Capacity 80 $\mathrm{M} \ell / \mathrm{d}$.

POLASEK P (1980) Methods and testing procedures for monitoring and evaluating waterworks performance. Paper presented at Int. Conf. SAFIL, Johannesburg.

POLASEK P and MUTLS (1995) Guidelines to coagulation and flocculation for surface waters.1: Design principles for coagulation and flocculation systems. PPA, Johannesburg.

PRIVATE COMMUNICATION (1983) Analysis of water carried out by NIWR, Pretoria (Letter of 19 April 1983),

TESARIK I (1961) Proudeni tekutiny porovitym prostredim (in Czech). SNTL, Praha. 